\title{
BMJ Open Clinical questions raised by providers in the care of older adults: a prospective observational study
}

\author{
Guilherme Del Fiol, ${ }^{1}$ Alice I Weber, ${ }^{2}$ Cherie P Brunker, ${ }^{3,4}$ Charlene R Weir ${ }^{1,5}$
}

To cite: Del Fiol G, Weber Al, Brunker CP, et al. Clinical questions raised by providers in the care of older adults: a prospective observational study. BMJ Open 2014;4: e005315. doi:10.1136/ bmjopen-2014-005315

- Prepublication history for this paper is available online. To view these files please visit the journal online (http://dx.doi.org/10.1136/ bmjopen-2014-005315).

Received 28 March 2014

Revised 13 June 2014 Accepted 17 June 2014

\section{CrossMark}

For numbered affiliations see end of article.

Correspondence to Dr Guilherme Del Fiol; guilherme.delfio@utah.edu

\section{ABSTRACT}

Objective: To characterise clinical questions raised by providers in the care of complex older adults in order to guide the design of interventions that can help providers answer these questions.

Materials and methods: To elicit clinical questions, we observed and audio recorded outpatient visits at three healthcare organisations. At the end of each appointment, providers were asked to identify clinical questions raised in the visit. Providers rated their questions based on their urgency, importance to the patient's care and difficulty in finding a useful answer to. Transcripts of the audio recordings were analysed to identify ageing-specific factors that may have contributed to the nature of the questions.

Results: We observed 36 patient visits with 10 providers at the three study sites. Providers raised 70 clinical questions (median of 2 clinical questions per patient seen; range 0-12), pursued $50(71 \%)$ and successfully answered $34(68 \%)$ of the questions they pursued. Overall, $36(51 \%)$ of providers' questions were not answered. Over one-third of the questions were about treatment alternatives and adverse effects. All but two clinical questions were motivated either directly or indirectly by issues related to ageing, such as the normal physiological changes of ageing and diseases with higher prevalence in the elderly.

Conclusions: The frequency of clinical questions was higher than in previous studies conducted in general primary care patient populations. Clinical questions were predominantly influenced by ageing-related issues. We propose a series of recommendations that may be used to guide the design of solutions to help providers answer their clinical questions in the care of older adults.

\section{INTRODUCTION}

In a seminal study, Covell et $a l^{1}$ observed that physicians raised two questions for every three patients seen in an outpatient setting. In $70 \%$ of the cases, these questions were not answered. Recent research has produced similar results, with little improvement in the three decades since Covell's study was published. According to a systematic review,

\section{Strengths and limitations of this study}

- This is the first study to observe clinical questions in the care of complex older adults.

- Our method included direct audio recorded observations of providers in multiple phases of outpatient care. This method allows more detailed and accurate data collection, since it relies on direct observations of care as opposed to provider's recall.

- The study findings raise important implications to improve the design of online health knowledge resources and electronic health record systems.

- Direct comparisons of question frequencies were not possible because we did not observe clinical questions in non-ageing and non-complex patients.

- The small number of sites and providers in each subgroup precluded a comparison of questions between different setting types and provider types.

estimates ranged from 0.2 to 1.9 clinical questions per patient seen, with less than half of these being pursued, and over $60 \%$ of questions not being answered. ${ }^{2}$ Unanswered clinical questions may represent knowledge gaps that have been associated with errors and reduced quality of care. ${ }^{3}$ This problem may be aggravated by the increasing volume of medical knowledge and patient complexity, especially associated with the ageing population. ${ }^{4-6}$

The number of older adults in our society is increasing dramatically as the 'Baby Boomers' start to age. In addition, the number of geriatricians available to care for them is not keeping pace with the increase. In fact, family physicians provide the majority of care for older adults, ${ }^{7}$ making education of these providers an important component of any programme to improve the quality of care. Caring for older adults is complex. Recent reviews assessing the quality of care provided for older adults have found significant deficits. For example, 
researchers found that only half of the vulnerable elderly living in the community received care that met quality indicators and only a third received care for those conditions that primarily impact the elderly. ${ }^{8}$ In another recent review, Askari et at found rates of appropriate care to be variable across studies and very low for many geriatric-related conditions, including dementia $(11-35 \%)$, depression $(27-41 \%)$ and osteoporosis $(34-43 \%)$.

Despite substantial previous research on providers' clinical questions, little is known about the specific characteristics of questions that arise in the care of ageing and complex patients. Knowledge of clinical questions in this patient population may be used to guide the design of interventions that help providers answer their questions and improve the care of older patients. The overall aim of this study was to address this gap. Specifically, we aimed at answering the following study questions: (1) How frequently do providers raise, pursue and answer their clinical questions? (2) How urgent, important to the patient's care and difficult to find an answer to are these clinical questions? (3) What types of questions are most commonly raised? (4) How often are these questions specific to geriatrics? (5) How do issues related to ageing affect these questions?

\section{METHODS}

\section{Study participants and sites}

All study participants reviewed and signed an informed consent to participate in the study. We recruited 10 experienced geriatricians, family physicians and nurse practitioners from outpatient settings at three healthcare organisations located in Utah: a geriatric clinic at the University of Utah, a geriatric clinic at the Salt Lake City Veterans Administration Medical Center (VAMC) and a community clinic at Intermountain Healthcare (Intermountain). We asked providers to identify complex patients who were scheduled for a visit during a typical clinic day. Complex patients were defined according to the Agency for Health Research and Quality (AHRQ) definition as those with "two or more chronic conditions where each condition may influence the care of the other condition(s) through limitations of life expectancy, interactions between drug therapies, and/or direct contraindications to therapy for one condition by other conditions themselves." 10

\section{Observations}

We focused on clinical questions as defined by Ely et $a l^{11}$ : "questions about medical knowledge that could potentially be answered by general sources such as textbooks and journals, not questions about patient data that would be answered by the medical record." To elicit clinical questions, we conducted patient care observations following the cognitive work analysis method, which is a group of techniques that integrate observation and interview for the purposes of understanding the constraints, resources, behaviour and cognitive goals of a work situation. ${ }^{12} \mathrm{~A}$ researcher (AIW) observed and audio recorded providers in all activities related to a patient visit, including preparing for the visits (eg, reviewing the patient's chart), interacting with the patient and concluding the visit (eg, documentation, medication prescription). Providers were asked to briefly summarise the case, listing the patient's problems, medications and visit goals. At the end of each appointment, providers were interviewed regarding the clinical questions that were raised in the visit. For each question identified, we asked the provider to rate its importance and urgency; level of confidence in the clinical domain of the question (eg, treatment of depression) and the level of difficulty of finding an answer to. These measures were obtained using a Likert scale format for the questionnaire. We also observed whether the question was pursued, asked providers whether a satisfactory answer was found and observed which information resources were used to answer it. The researcher contacted providers for a follow-up interview about questions that were not answered in the visit within 4 weeks following the observation session.

\section{Data analysis}

Audio recordings were transcribed and de-identified for analysis. Two investigators (GDF, CRW) independently reviewed the transcripts to identify clinical questions. We identified questions that were both explicitly stated by providers in the postvisit interview and inferred from providers' verbalisations and observed informationseeking behaviour. Next, annotations were compared assisted by the researcher who conducted the observations, and discrepancies were resolved by discussion until the investigators reached consensus. The final set of questions was coded independently by two investigators (GDF, AIW) according to Ely's taxonomy of clinical questions. $^{11}$ In this phase, disagreements were also resolved by consensus.

Clinical questions were also coded in terms of the degree to which ageing-related factors contributed to a question. An ageing factor was defined as a patient characteristic that is exclusive to, or more common in, ageing patients and that motivates or modifies the nature of a clinical question. Factors were identified, and questions were coded using the constant comparison method. ${ }^{13}$ In the first round, the four study authors independently proposed candidate factors for a subset of 20 questions. Next, the factors proposed by each investigator were reconciled through group consensus (one of the authors is an experienced geriatrician). In the second round, investigators used the set of reconciled factors to code another set of 35 questions. In this round, new factors were proposed and the definition of previous factors was refined through group consensus. In the third and final round, investigators coded the remaining questions resolving disagreements by 
consensus. No changes to the factors were necessary in this final round.

Finally, we conducted univariate analyses to test the association between urgency, importance, provider confidence and time pressure as predictors for the decision to pursue. Statistical significance was tested with the Fisher's exact test. We also assessed the association between number of questions per patient and number of questions pursued. Statistical significance was tested with analysis of variance, with the binary decision to pursue as the grouping variable.

\section{RESULTS}

Frequency of clinical questions raised, pursued and answered

Providers raised 70 clinical questions in 36 patient visits (average of 1.9 questions per patient seen; median of 2 questions per patient seen; range 0-12 questions), pursued $50(71 \%)$ and successfully answered $34(68 \%)$ of the questions they pursued. Most questions were pursued during the visit versus the follow-up period (48 vs 2 out of 50 questions pursued). Overall, 36 (51\%) of providers' clinical questions were not answered.

\section{Importance, urgency, confidence and difficulty}

Providers considered $42 \%$ (mean rating=3.0; 1=not urgent; $5=$ very urgent) of their questions to be urgent or very urgent, and $81 \%$ (mean rating $=4.1 ; 1=$ not important; 5 =very important) to be important or very important for the patient's care. Of the questions that were left unanswered, $45 \%$ were considered to be important or very important and $8 \%$ were considered to be urgent or very urgent. In $61 \%$ of the questions (mean rating $=3.8$; $1=$ not confident; $5=$ very confident), providers felt that they were confident or very confident regarding their overall knowledge in the domain of the question. Providers perceived that only $14 \%$ (mean rating $=2.2$; $1=$ not difficult; $5=$ very difficult) of the questions they pursued were difficult or very difficult to find an answer to. None of the associations between the independent variables (urgency, importance, provider confidence and time pressure) and a question being pursued were significant (table 1). Physicians were more likely to pursue

Table 1 Association between urgency, importance, provider confidence and time pressure as predictors for the decision to pursue a clinical question

\begin{tabular}{llll}
\hline Predictor & $\begin{array}{l}\text { Fisher's } \\
\text { exact } \\
\text { test }\end{array}$ & $\begin{array}{l}\text { Degrees } \\
\text { of } \\
\text { freedom }\end{array}$ & p Value \\
\hline Urgency & 0.54 & 1 & 0.64 \\
Importance & 0.37 & 1 & 0.65 \\
Provider confidence & 0.99 & 1 & 0.36 \\
Time & 2.2 & 1 & 0.34 \\
\hline
\end{tabular}

questions for patients whose care generated a larger number of questions $(\mathrm{F}(1,68)=4.076 ; \mathrm{p}=0.047)$.

\section{Types of clinical questions and ageing factors}

Table 2 shows the frequency of clinical questions according to Ely's taxonomy comparing to five previous studies that used the same taxonomy. Over one-third of the questions were about treatment alternatives and adverse effects. Most questions (68 out of 70;97\%) were directly or indirectly related to 1 of 10 ageing-specific factors (table 3). Over half $(40 ; 57 \%)$ of the clinical questions were related to treatment factors, specifically treatment choice $(18 ; 26 \%)$, prescribing considerations $(13 ; 19 \%)$ and managing side effects $(9 ; 13 \%)$. Table 3 proposes a set of recommendations to guide the design of online knowledge resources and electronic health record (EHR) systems in light of the ageing factors listed in table 3.

\section{DISCUSSION}

We characterised the clinical questions raised by providers in the care of complex older adults. We found that providers raised three times more questions (1.9 vs 0.6

Table 2 Clinical questions classified according to Ely's taxonomy and compared with pooled data from five previous studies

\begin{tabular}{|c|c|c|}
\hline Question type & $\begin{array}{l}\text { Previous } \\
\text { studies (\%) }\end{array}$ & $\begin{array}{l}\text { Current } \\
\text { study (\%) }\end{array}$ \\
\hline $\begin{array}{l}\text { What is the drug of choice } \\
\text { for condition } x \text { ? }\end{array}$ & 10 & 16 \\
\hline $\begin{array}{l}\text { What is the cause of } \\
\text { symptom } x \text { ? }\end{array}$ & 10 & 3 \\
\hline $\begin{array}{l}\text { How should I treat condition } \\
\mathrm{x} \text { (not limited to drug } \\
\text { treatment)? }\end{array}$ & 7 & 8 \\
\hline $\begin{array}{l}\text { What is the cause of } \\
\text { physical finding } x ?\end{array}$ & 7 & 3 \\
\hline $\begin{array}{l}\text { What test is indicated in } \\
\text { situation } \mathrm{x} \text { ? }\end{array}$ & 6 & 5 \\
\hline What is the dose of drug $x ?$ & 6 & 4 \\
\hline $\begin{array}{l}\text { Can drug } x \text { cause (adverse) } \\
\text { finding } y ?\end{array}$ & 5 & 13 \\
\hline $\begin{array}{l}\text { What is the cause of test } \\
\text { finding } x \text { ? }\end{array}$ & 4 & 1 \\
\hline $\begin{array}{l}\text { Could this patient have } \\
\text { condition } x ?\end{array}$ & 4 & 1 \\
\hline $\begin{array}{l}\text { How should I manage } \\
\text { condition } \mathrm{x} \text { (not specifying } \\
\text { diagnostic or therapeutic)? }\end{array}$ & 4 & 0 \\
\hline $\begin{array}{l}\text { What is the prognosis of } \\
\text { condition } x \text { ? }\end{array}$ & 2 & 1 \\
\hline $\begin{array}{l}\text { What are the manifestations } \\
\text { of condition } \mathrm{x} \text { ? }\end{array}$ & 2 & 0 \\
\hline $\begin{array}{l}\text { What conditions or risk } \\
\text { factors are associated with } \\
\text { condition y? }\end{array}$ & 2 & 1 \\
\hline
\end{tabular}


Table 3 Frequency of clinical questions per ageing factor

\begin{tabular}{|c|c|c|c|}
\hline Aging factor & Frequency & Definition & Examples \\
\hline $\begin{array}{l}\text { Special considerations } \\
\text { when choosing optimal } \\
\text { treatment }\end{array}$ & $18(26 \%)$ & $\begin{array}{l}\text { Selection of an optimal individualised } \\
\text { treatment considering ageing factors such as } \\
\text { risk/benefit and comorbidities. Successful } \\
\text { outcome is more difficult because of } \\
\text { underlying ageing issues }\end{array}$ & $\begin{array}{l}\text { What is the preferred A1c goal in } \\
\text { the ageing population? } \\
\text { What is the best treatment choice } \\
\text { for diabetes when the patient also } \\
\text { has heart failure? }\end{array}$ \\
\hline $\begin{array}{l}\text { Special prescribing } \\
\text { considerations }\end{array}$ & $13(19 \%)$ & $\begin{array}{l}\text { Medication prescription needs to be adjusted } \\
\text { to maximise compliance, and minimise side } \\
\text { effects/organ damage (eg, by adjusting } \\
\text { medication dose) }\end{array}$ & $\begin{array}{l}\text { What is the geriatric dose of } \\
\text { buspar for depression? } \\
\text { What is the CrCl cut-off for } \\
\text { alendronate? }\end{array}$ \\
\hline $\begin{array}{l}\text { Complex management of } \\
\text { side effects }\end{array}$ & $9(13 \%)$ & $\begin{array}{l}\text { Consideration of side effects. Issues such as } \\
\text { polypharmacy and lower medication tolerance } \\
\text { contribute to a higher incidence of and more } \\
\text { complexity in managing side effects }\end{array}$ & $\begin{array}{l}\text { Is hallucination a side effect of } \\
\text { rivastigmine? } \\
\text { Is there adjunct treatment of } \\
\text { depression that does not cause } \\
\text { drowsiness? }\end{array}$ \\
\hline Condition prevalence & $8(11 \%)$ & $\begin{array}{l}\text { Condition related to the questions is much } \\
\text { more prevalent in the elderly. Questions } \\
\text { related to these conditions would be less } \\
\text { common in non-ageing patients }\end{array}$ & $\begin{array}{l}\text { What is the best treatment choice } \\
\text { for cognitive dysfunction? }\end{array}$ \\
\hline $\begin{array}{l}\text { Understanding other } \\
\text { provider's rationale }\end{array}$ & $6(9 \%)$ & $\begin{array}{l}\text { Unable to interpret rationale of other providers } \\
\text { due to lack of enough information (eg, } \\
\text { prescription without reason, diagnosis without } \\
\text { explanation). Complex ageing patients are } \\
\text { often cared for by multiple providers }\end{array}$ & $\begin{array}{l}\text { What are these eye drops used } \\
\text { for? } \\
\text { What are the indications of } \\
\text { concomitant use of aspirin and } \\
\text { warfarin? }\end{array}$ \\
\hline Dx testing considerations & $4(6 \%)$ & $\begin{array}{l}\text { Ageing risk factors need to be considered in } \\
\text { the choice of diagnostic intervention }\end{array}$ & $\begin{array}{l}\text { Is contrast indicated for chest } \\
\text { X-ray to assess aspiration in a } \\
\text { patient with GERD? }\end{array}$ \\
\hline Access to health services & $4(6 \%)$ & $\begin{array}{l}\text { Health services that are more commonly } \\
\text { needed or that have special requirements in } \\
\text { elderly patients }\end{array}$ & $\begin{array}{l}\text { Where should I refer this patient } \\
\text { for mental health? }\end{array}$ \\
\hline Difficult diagnosis & $4(6 \%)$ & $\begin{array}{l}\text { Difficult diagnosis due to underlying ageing } \\
\text { factors (eg, multiple comorbidities, different } \\
\text { presentation). Difficult to interpret new set of } \\
\text { symptoms/signs/findings in light of the overall } \\
\text { patient's picture }\end{array}$ & $\begin{array}{l}\text { Why is this patient osteopaenic? } \\
\text { What is the cause of this patient's } \\
\text { weight loss? }\end{array}$ \\
\hline Gender considerations & $1(1 \%)$ & $\begin{array}{l}\text { Decisions in the elderly that are affected by } \\
\text { gender (eg, different statin dose, different } \\
\text { osteoporosis treatment) }\end{array}$ & $\begin{array}{l}\text { How do I manage cardiovascular } \\
\text { risk in elderly women? }\end{array}$ \\
\hline Need for geriatric tool & $1(1 \%)$ & $\begin{array}{l}\text { Need for tools (eg, assessment tools) that are } \\
\text { specific for geriatrics }\end{array}$ & $\begin{array}{l}\text { Where can I find a template for } \\
\text { haematology-oncology } \\
\text { assessment }\end{array}$ \\
\hline No ageing factor & $2(3 \%)$ & $\begin{array}{l}\text { Question not motivated or mediated by ageing } \\
\text { and answer is not ageing-specific }\end{array}$ & $\begin{array}{l}\text { Where can I find patient education } \\
\text { information on cholesterol diet? }\end{array}$ \\
\hline
\end{tabular}

questions per patient seen) than in previous studies not focused on complex ageing patients. This higher rate of questions may be attributed to the complexity of patients seen and to ageing factors. We also identified a set of ageing-specific factors that motivated or affected most of the questions. These factors can be used to guide the design of solutions that can answer these questions more directly.

Our study has a few important strengths. This is the first study to observe clinical questions in the care of complex older adults. Investigating these questions is important because the ageing population is rapidly increasing ${ }^{5}$ and elderly patients with multiple comorbidities are more difficult to manage with available clinical practice guidelines, ${ }^{4}$ which lead to significant deficits in the quality of care. $^{8}{ }^{14}$ As a second strength, our method included direct audio recorded observations of providers in multiple phases of outpatient care. Most previous studies elicited clinical questions in after-visit interviews or relied on providers to keep their own record of their questions. ${ }^{2}$ Our method allows more detailed and accurate data collection, since it relies on direct observations of care as opposed to provider's recall, which could involve a possible bias.

Over half of the questions raised in our study were left unanswered and providers rated close to half of these questions as important or very important for the 
Table 4 Ageing factors and implications for the design of online knowledge resources and electronic health record (EHR) systems

Ageing factor
Special considerations when
choosing optimal treatment
and diagnostic testing

Special prescribing considerations

Complex management of side effects

Understanding other provider's rationale

Access to health services

\section{Implications for design}

Online knowledge resources could provide specific recommendations to help providers tailor treatment and choose diagnostic tests considering ageing issues such as risk/ benefit, comorbidities, functional status and social support. These recommendations should be easily accessible/filtered by the resource's search engine based on the patient's age

EHR systems should capture patient's life goals and integrate them into the patient's treatment plan

Online knowledge resources could provide seamless access to age-specific guidance on dose adjustment, adherence issues in older adults and ageing-specific contraindications

EHR systems could propose and automatically calculate adjusted medication dosing when indicated due to ageing factors

Based on a patient's side effects and current medications, online resources could provide likely side effects for combinations of medications often seen in older patients. Online resources could automatically construct a side effect profile based on the medications documented on the patient's EHR. In addition, online resources could enable providers to simulate alternate medication scenarios and compare side effect profiles of alternate scenarios Providers should be able to document the rationale for their decisions (eg, prescribing a medication, discontinuing a medication, ordering a diagnostic test) in the patient's EHR and link the rationale to the decision. This documentation should support identification of how the provider addressed patient preferences, social support and functional status

Based on a location of interest and the patient's age, the EHR could automatically link to information on health services available in the area

\section{Examples}

"What is the preferred A1c goal in the ageing population?"

Provide recommendations on how to adjust the A1c goal given factors such as the patient's age, preferences and life expectancy

"What is the best treatment choice for diabetes when the patient also has heart failure?"

Provide treatment recommendations in the presence of most common comorbidities

"What is the geriatric dose of buspar for depression?"

Allow the user to provide the patient's age in the search process and highlight the geriatric dose in the user interface. When prescribing a medication or reviewing a patient's medications list, display an icon next to a medication that is potentially inappropriate for ageing patients. Hovering the mouse over this icon provides an explanation and a suggested alternative

"Which of the patient's medication may be causing hallucination?"

Rather than scanning the list of side effects for each of the patient's current medications, EHRs could automatically send the side effect and the patient's medications list to online knowledge resources, which would return a table with the medications and their likelihood of causing the side effect of interest

"What are the indications of concomitant use of aspirin and warfarin?"

When hovering over a medication in the patient's medication list, the EHR shows the rationale of the prescriber for prescribing the medication

"Where should I refer this patient for mental health?"

A link from the EHR could automatically retrieve mental health facilities within the patient's location patient's care. These unanswered questions may contribute to issues that disproportionally affect the elderly population, such as increased adverse events, ${ }^{6}$ 15-20 inappropriate medication prescription, treatment failure and adverse drug withdrawal events. ${ }^{14}$

Consistent with previous studies, providers did not pursue over half of their questions. When providers pursued a question, they were successful most of the time. This might be an indication that providers selfselect questions that can be answered with little effort. In our study, providers perceived that only $14 \%$ of the questions pursued were difficult to answer. Providers were more likely to pursue questions for patients whose care generated a larger number of questions. It is possible that these patients were more complex and therefore required more careful deliberation. 
Compared with previous studies, we found a higher frequency of questions related to treatment alternatives and adverse effects. This finding could be explained by the presence of ageing-specific factors that motivated or affected nearly all questions observed in our study. These factors commonly constrain or alter treatment choices, making treatment decisions more complex and often not amenable to available evidence-based guidelines. ${ }^{4}$ This is consistent with a study by Merten et $a l^{18}$ which found the inability to apply existing knowledge to a new and complex situation to be an important contributor to adverse events in older patients. Providers in our study were often faced with the need to personalise treatment goals according to individual factors, such as undesired effects of treatment, comorbidities, patients' priorities and life expectancy. As healthcare delivery systems strive to provide patient-centred care, the need to personalise and integrate a patient's specific context will become increasingly important.

\section{Potential solutions}

As suggested in table 4, ageing-specific factors should be considered in the design of online knowledge resources and EHR systems. The design considerations provided in table 4 are technically feasible and international standards are available to enable automated links between EHR systems and online knowledge resources. ${ }^{21}$ These standards are being widely adopted in the USA as a requirement for EHR certification. ${ }^{22}$

Since providers rarely pursue questions after a patient's visit, solutions need to provide answers to providers' questions rapidly, ideally in less than a minute. Yet, in a healthcare environment where providers spend on average $15 \mathrm{~min} /$ patient visit, ${ }^{23}{ }^{24}$ constraining information seeking to the time frame of a patient encounter may limit providers to pursuing easier questions. One alternative is to design interventions that help providers record their questions and pursue them at their convenience. Answers to these questions could be automatically stored in the patient's EHR and shared with other providers who manage similar patients through technologies like social media and recommender systems. In addition, automated analysis of recorded questions could be used to help providers define their lifelong learning goals as a component of Maintenance of Certification. ${ }^{25}{ }^{26}$ This form of self-directed learning could be more effective and compatible with the adult learning style than traditional forms of continuing medical education. ${ }^{26} 27$

Online knowledge resources could be designed to go beyond reporting of individual studies, and to supporting simulations of combinations of complex variables. A high level of integration is required in order to individualise or for tailor treatment, but few single studies address any specific combination of risk, patient preferences, expected life expectancy and comorbidities. This requirement is not only needed in the older population, but also in other areas, such as children with special needs, immigrant populations and other unique populations.

\section{Limitations}

We did not observe clinical questions in non-ageing and non-complex patients. Therefore, direct comparisons of question frequencies were not possible. The small number of sites and providers in each subgroup, along with the presence of several potential confounders, precluded a comparison of questions between different setting types (eg, academic vs community clinic) and provider types (eg, family physicians vs geriatricians, nurse practitioners vs physicians). As in previous similar studies, the presence of an observer may have stimulated questions and information-seeking behaviour. To minimise this risk, we observed providers in their typical busy routine as unobtrusively as possible, and asked them to carry out their work as they would normally do. In addition, observation studies have provided more reliable results than other methods, such as self-report and surveys, which are prone to recall bias. ${ }^{2}$ Finally, the 4-week time frame for follow-up may have introduced recall bias, as in previous studies most providers pursued their clinical questions within $24 \mathrm{~h}$ of a patient encounter. $^{2}$

\section{Future studies}

Studies are needed to design and assess interventions that help providers' decision-making in ageing and complex patients. As suggested in the previous sections, our findings provide important insights for intervention design. Moreover, larger studies are needed to enable subgroup comparisons such as the ones described above.

\section{CONCLUSION}

We found that providers raised a large number of clinical questions in the care of complex older adults and half of these questions were not answered. Compared with previous studies in younger adults, clinical questions in the care of the older population were raised three times more often. We also found a relatively higher rate of questions related to treatment alternatives and adverse effects. Most of the questions were motivated or mediated by factors specific to ageing. When unanswered, these questions may contribute to issues that are more prevalent in the elderly, such as an increased rate of adverse drug events. Our findings may be used to help guide the design of information delivery interventions that help providers answer their clinical questions in the care of older adults.

\section{Author affiliations}

${ }^{1}$ Department of Biomedical Informatics, University of Utah, Salt Lake City, Utah, USA

${ }^{2}$ Spencer S. Eccles Health Sciences Library, University of Utah, Salt Lake City, Utah, USA

${ }^{3}$ Division of Geriatrics, Department of Internal Medicine, University of Utah, Salt Lake City, Utah, USA

${ }^{4}$ Intermountain Healthcare, Salt Lake City, Utah, USA

${ }^{5}$ VA Medical Center, Salt Lake City, Utah, USA 
Contributors GDF provided substantial contributions to conception and design, and analysis and interpretation of data; drafting the article and final approval of the version to be published. AIW provided substantial contributions to acquisition of data and analysis and interpretation of data; revising the article critically for important intellectual content and final approval of the version to be published. CPB provided substantial contributions to analysis and interpretation of data; revising the article critically for important intellectual content and final approval of the version to be published. CRW provided substantial contributions to conception and design, and analysis and interpretation of data; revising the article critically for important intellectual content and final approval of the version to be published.

Funding This study was funded by the Utah Center on Aging Pilot Program and by grant number K01HS018352 from the Agency for Healthcare Research and Quality.

Competing interests None.

Ethics approval This study was approved by the University of Utah Institutional Review Board under study number 00051227 and Intermountain IRB study number RMS1024116.

Provenance and peer review Not commissioned; externally peer reviewed.

Data sharing statement No additional data are available.

Open Access This is an Open Access article distributed in accordance with the Creative Commons Attribution Non Commercial (CC BY-NC 4.0) license, which permits others to distribute, remix, adapt, build upon this work noncommercially, and license their derivative works on different terms, provided the original work is properly cited and the use is non-commercial. See: http:// creativecommons.org/licenses/by-nc/4.0/

\section{REFERENCES}

1. Covell DG, Uman GC, Manning PR. Information needs in office practice: are they being met? Ann Intern Med 1985;103:596-9.

2. Del Fiol G, Workman TE, Gorman PN. Clinical questions raised by clinicians at the point of care: a systematic review. JAMA Intern Med 2014;174:710-18

3. Leape LL, Bates DW, Cullen DJ, et al. Systems analysis of adverse drug events. ADE Prevention Study Group. JAMA 1995;274:35-43.

4. Boyd CM, Darer J, Boult C, et al. Clinical practice guidelines and quality of care for older patients with multiple comorbid diseases: implications for pay for performance. JAMA 2005;294:716-24.

5. Colwill JM, Cultice JM, Kruse RL. Will generalist physician supply meet demands of an increasing and aging population? Health Aff 2008;27:w232-41.

6. Huang ES, Laiteerapong N, Liu JY, et al. Rates of complications and mortality in older patients with diabetes mellitus: the diabetes and aging study. JAMA Intern Med 2014;174:251-8.

7. Mold JW, Fryer GE, Phillips RL Jr, et al. Family physicians are the main source of primary health care for the Medicare population. Am Fam Physician 2002;66:2032.
8. Wenger NS, Solomon DH, Roth $\mathrm{CP}$, et al. The quality of medical care provided to vulnerable community-dwelling older patients. Annals Intern Med 2003;139:740-7.

9. Askari M, Wierenga PC, Eslami S, et al. Assessing quality of care of elderly patients using the ACOVE quality indicator set: a systematic review. PLOS ONE 2011;6:e28631.

10. Recovery Act 2009 Limited Competition OS ARRA: Comparative Effectiveness Research to Optimize Prevention and Healthcare Management for the Complex Patient (R21), 2013.

11. Ely JW, Osheroff JA, Gorman PN, et al. A taxonomy of generic clinical questions: classification study. BMJ 2000;321:429-32.

12. Vicente KJ. Cognitive work analysis: toward safe, productive, and healthy computer-based work. Taylor \& Francis, 1999.

13. Glaser BG. The constant comparative method of qualitative analysis Soc Probl 1965;12:436-45.

14. Opondo D, Eslami S, Visscher S, et al. Inappropriateness of medication prescriptions to elderly patients in the primary care setting: a systematic review. PLOS ONE 2012;7:e43617.

15. Tache SV, Sonnichsen A, Ashcroft DM. Prevalence of adverse drug events in ambulatory care: a systematic review. Ann Pharmacother 2011;45:977-89.

16. Budnitz DS, Lovegrove MC, Shehab N, et al. Emergency hospitalizations for adverse drug events in older Americans. $N$ Engl J Med 2011;365:2002-12.

17. Chiatti C, Bustacchini S, Furneri G, et al. The economic burden of inappropriate drug prescribing, lack of adherence and compliance, adverse drug events in older people: a systematic review. Drug Saf 2012;35(Suppl 1):73-87.

18. Merten $\mathrm{H}$, Zegers $\mathrm{M}$, de Bruijne $\mathrm{MC}$, et al. Nature, preventability and causes of adverse events in hospitalised older patients. Age Ageing 2013:42:87-93.

19. Obreli-Neto PR, Nobili A, de Oliveira Baldoni A, et al. Adverse drug reactions caused by drug-drug interactions in elderly outpatients: a prospective cohort study. Eur J Clin Pharmacol 2012;68:1667-76.

20. Sears N, Baker GR, Barnsley J, et al. The incidence of adverse events among home care patients. Int J Qual Health Care 2013;25:16-28.

21. Del Fiol G, Huser V, Strasberg HR. Implementations of the HL7 Context-Aware Knowledge Retrieval ("Infobutton") Standard: challenges, strengths, limitations, and uptake. J Biomed Inform 2012;45:726-35.

22. Office of the National Coordinator for Health Information Technology (ONC) DoHaHS. Health Information Technology: Standards, Implementation Specifications, and Certification Criteria for Electronic Health Record Technology, 2014 Edition, Final Rule. 77, 2012:130.

23. Mechanic D, McAlpine DD, Rosenthal M. Are patients' office visits with physicians getting shorter? N Engl J Med 2001;344:198-204.

24. Tai-Seale M, McGuire TG, Zhang W. Time allocation in primary care office visits. Health Serv Res 2007:42:1871-94.

25. Levinson W, Holmboe E. Maintenance of certification in internal medicine: facts and misconceptions. Arch Intern Med 2011;171:174-6.

26. Dhaliwal G. Known unknowns and unknown unknowns at the point of care. JAMA Intern Med 2013;173:1959-61

27. Miles $P$. Health information systems and physician quality: role of the American board of pediatrics maintenance of certification in improving children's health care. Pediatrics 2009;123(Suppl 2): S108-10. 